\title{
CONF-941144--112
}

\section{A SPECTRAL EFFECT ON PHASE EVOLUTION IN NEUTRON-IRRADIATED ALUMINUM?*}

K. FARRELL, Oak Ridge National Laboratory, P. O. Box 2008, Oak Ridge. TN 37831

\begin{abstract}
It is proposed that the spatial distribution of transmutation-produced silicon precipitates formed in aluminum by capture of thermal neutrons is systematically modified by the fast neutron portion of the spectrum, and the tensile strength is altered accordingly. The concept is used to rationalize some previously erratic tensile data.
\end{abstract}

\section{THE THESIS}

Many water-cooled research reactors contain aluminum alloy components. The aluminum atoms capture thermal neutrons and are transformed to silicon by the reactions ${ }^{27} \mathrm{Al}(\mathrm{n}, \gamma)^{28} \mathrm{Al} \rightarrow{ }^{28} \mathrm{Si}$ $+\beta$. The cross section has a value of $230 \mathrm{mb}$ for $2200 \mathrm{~m} / \mathrm{s}(E=0.025 \mathrm{eV})$ neutrons. These reactors operate at water temperatures between $45^{\circ}$ and $100^{\circ} \mathrm{C}$. which correspond to homologous temperatures of 0.34 to $0.4 \mathrm{~T}_{\mathrm{m}}$ for aluminum. at which vacancies are mobile. The solubility of silicon is negligible and it forms precipitate particles ${ }^{1}$. In high flux reactors it is not uncommon to find reactor components with neutron-generated silicon concentrations of $5 \mathrm{wt} \%$ or more. At such levels the silicon precipitate will dominate the radiation-induced increases in strength. The strength will depend not only on the volume fraction of silicon but also on its spatial distribution. A finely-divided phase will cause more strengthening than the same volume fraction in a coarse distribution.

This raises the possibility of a spectral effect in which the thermal fluence will control the volume fraction of silicon phase. and some other portion of the spectrum may determine the size and concentration of the precipitate particles. It is well-known that excess point defects produced by atomic displacements can raise diffusion rates and cause considerable phase instability and redistribution of solutes ${ }^{2.3}$. which can result in accelerated Ostwald ripening of a precipitate phase ${ }^{+}$. In aluminum. some point defects are created by atomic recoils from the $(n, \gamma)$ reactions but the cross section is small. $\approx 3 \mathrm{~b}$, compared with a value of $\approx 1200 \mathrm{~b}$ for displacements by fast neutrons with energies $>0.1 \mathrm{Mev}$. Fast neutrons may make an additional contribution to precipitate ripening via cascade dissolution. which will release silicon atoms into the point defect streams and may be more destructive of smaller particles than larger ones. It would not be unreasonable, then. to expect that the microstructure and corresponding tensile strength of irradiated aluminum should be sensitive to the neutron spectrum, as expressed through the ratio of thermal-to-fast flux, $\Phi_{\mathrm{th}} / \Phi_{\mathrm{f}}$. A soft spectrum, i.e. a high ratio of $\Phi_{\mathrm{th}} / \Phi_{\mathrm{f}}$, will induce less displacements per unit silicon atom and should retard the ripening process. resulting in a finer distribution of the silicon phase and more strengthening; and vice versa.

\footnotetext{
*Research supported by the Division of Materials Sciences, U.S. DOE under Contract DE-AC05-840R21400 with Martin Marietta Energy Systems, Inc.
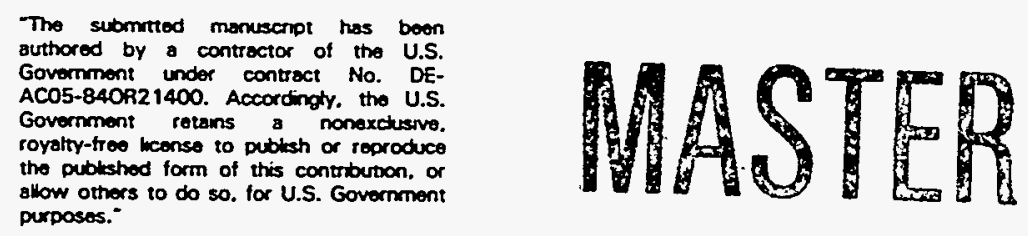


\section{DISCLAIMER}

Portions of this document may be illegible in electronic image products. Images are produced from the best available original document. 


\section{THE EVIDENCE}

The evidence for the spectral effect stems from the tensile strength data of Weeks et $\mathrm{a}^{5,6}$ for 6061-T6 aluminum alloy. This alloy has a nominal composition of $\mathrm{Al}-1.0 \mathrm{Mg}-0.6 \mathrm{Si}$ and in its $\mathrm{T} 6$ condition is quenched and tempered to produce a microstructure of fine, needle-like $\mathrm{Mg}_{2} \mathrm{Si}$ precipitates. Weeks' test specimens were cut from reactor components irradiated for long periods- in the heavy-water-cooled High Flux Beam Reactor (HFBR) at Brookhaven National Laboratory. The reactor coolant inlet and outlet temperatures were $55^{\circ}$ and $65^{\circ} \mathrm{C}$, respectively. The data are displayed in Fig. 1, together with a set of data obtained ${ }^{7.8}$ for exposures in the lightwater-cooled High Flux Isotope Reactor (HFIR) at Oak Ridge National Laboratory, with inlet and outlet temperatures of $44^{\circ} \mathrm{C}$ and $67^{\circ} \mathrm{C}$. The data are plotted against thermal fluence in the upper part of the figure and against fast fluence in the lower part. In both parts, the HFIR data are a smoothly increasing function of fluence, whereas the HFBR data show considerable scatter.
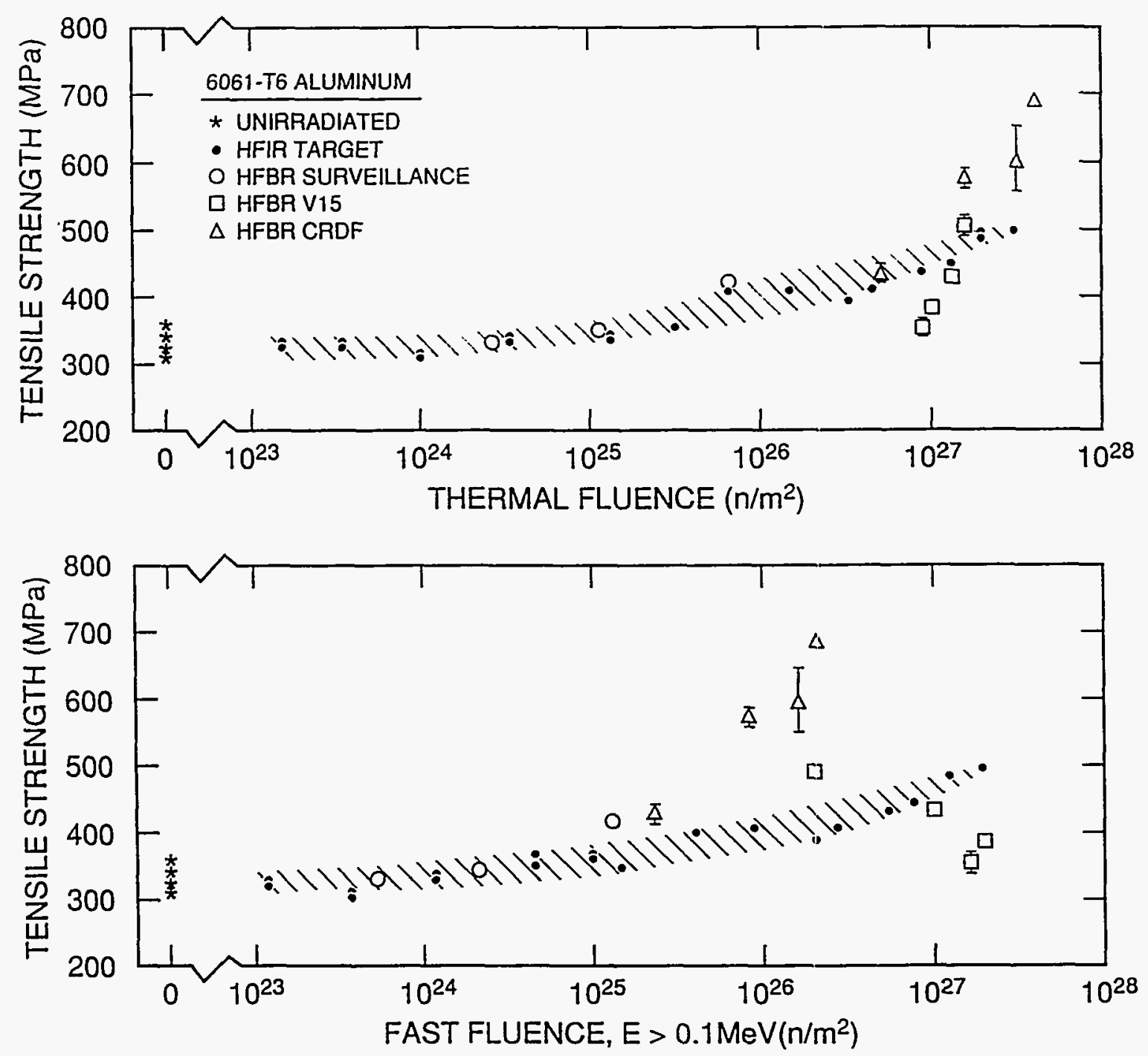

Figure 1. Fluence dependencies of tensile strengths of 6061-T6 alumininum alloy irradiated in the $\mathrm{HFBR}^{5,6}$ and the HFIR ${ }^{7,8}$. 
The picture changes when the data in Fig. 1 are assessed in terms of their $\Phi_{\mathrm{th}} / \Phi_{\mathrm{f}}$ ratios. The HFIR test specimens were all irradiated in the flux trap where the fluxes are high and the spectrum is fairly hard, with a $\Phi_{\mathrm{th}} / \Phi_{\mathrm{f}}$ ratio in a very narrow range of 1.7 to 2.5 . Hence, from the spectral effects perspective. they should yieid smooth plots against both thermal fluence and fast fluence. The HFBR materials were exposed at different locations in the reactor, some inside the core, others away from the core in the softer spectra of the heavy-water reflector. Their $\Phi_{\mathrm{th}} / \Phi_{\mathrm{f}}$ ratios vary from 0.5 to 20 . We should not attempt to represent these data by a single line. Rather, each datum should belong to one of a family of curves each depicting a narrow range of $\Phi_{\mathrm{th}} / \Phi_{\mathrm{f}}$ ratio and each following a fluence response of similar form to the HFIR specimens, as shown in Fig. 2. Here, the HFBR curves straddle the HFIR curves and share a pattern of smoothly-varying behavior with both fast and thermal fluences. The curves merge to the unirradiated strength level at thermal fluences below $1 \times 10^{25} \mathrm{n} / \mathrm{m}^{2}$ and fast fluences below $1 \times 10^{24} \mathrm{n} / \mathrm{m}^{2}$, where the transmutation-produced silicon levels are less than about $0.02 \%$.
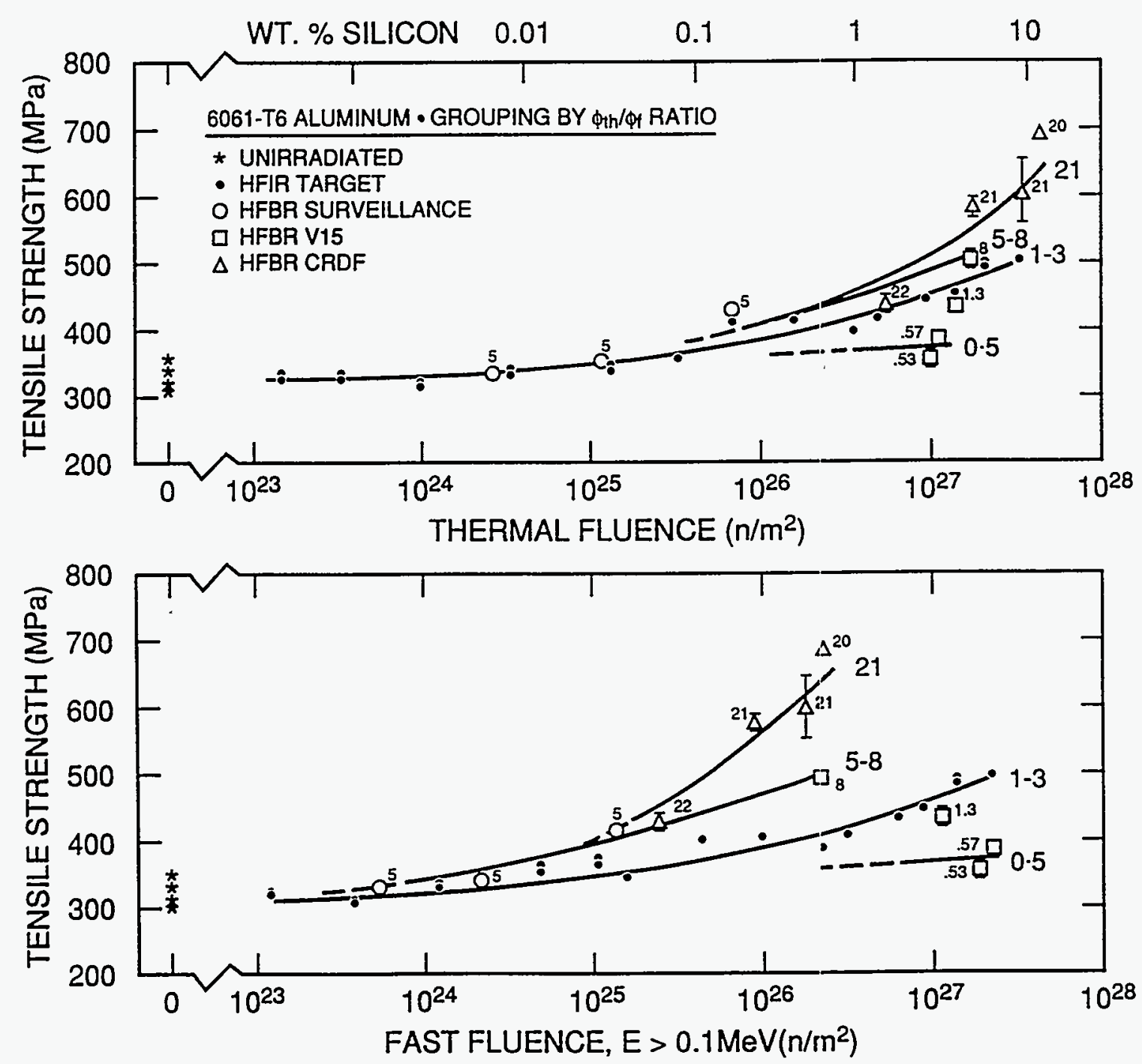

Figure 2. Data from Fig. 1 assessed by $\Phi_{\mathrm{th}} / \ddot{\Phi}_{\mathrm{f}}$ ratio. 
At a common thermal neutron fluence. i.e. at equal levels of transmutation-produced silicon, those HFBR specimens with larger $\Phi_{\mathrm{th}} / \Phi_{\mathrm{f}}$ ratios than the HFIR specimens are stronger than the HFIR specimens, and those with smaller ratios are weaker. In this scenario, a HFBR material with a larger $\Phi_{\mathrm{th}} / \Phi_{\mathrm{f}}$ ratio than the HFIR specimens should have a finer distribution of silicon precipitates than the corresponding HFIR specimen.

Comparison of microstructural data for the highest fluence HIFIR specimens and the high fluence, high $\Phi_{\mathrm{th}} / \Phi_{\mathrm{f}}$ ratio HFBR specimens at silicon levels of 7 to $9 \%$ agree with this interpretation. Details of the microstructural examinations are described elsewhere ${ }^{8.9}$. The most essential observation for the present purposes is seen in Fig.3, where it is clear that the dark, spherical objects, which are silicon-rich particles, are much smaller and more numerous in the HFBR specimen. Other microstructural changes involved the nearly-complete re-solution of the original, fine, acicular precipate of $\mathrm{Mg}_{2} \mathrm{Si}$ phase in both cases. Flakes of a silicon-rich phase were formed on grain boundaries, and there seemed to be more of them in the HFIR material. Zones on each side of grain boundaries were denuded of the silicon-rich phase, the zones being wider for the HFIR materials. Voids were present in the HFIR material and were coated with silicon; voids were absent in the HFBR materials. The silicon-rich precipitates were amorphous. Intermetallic inclusions, which were originally crystalline. became amorphous during irradiation.
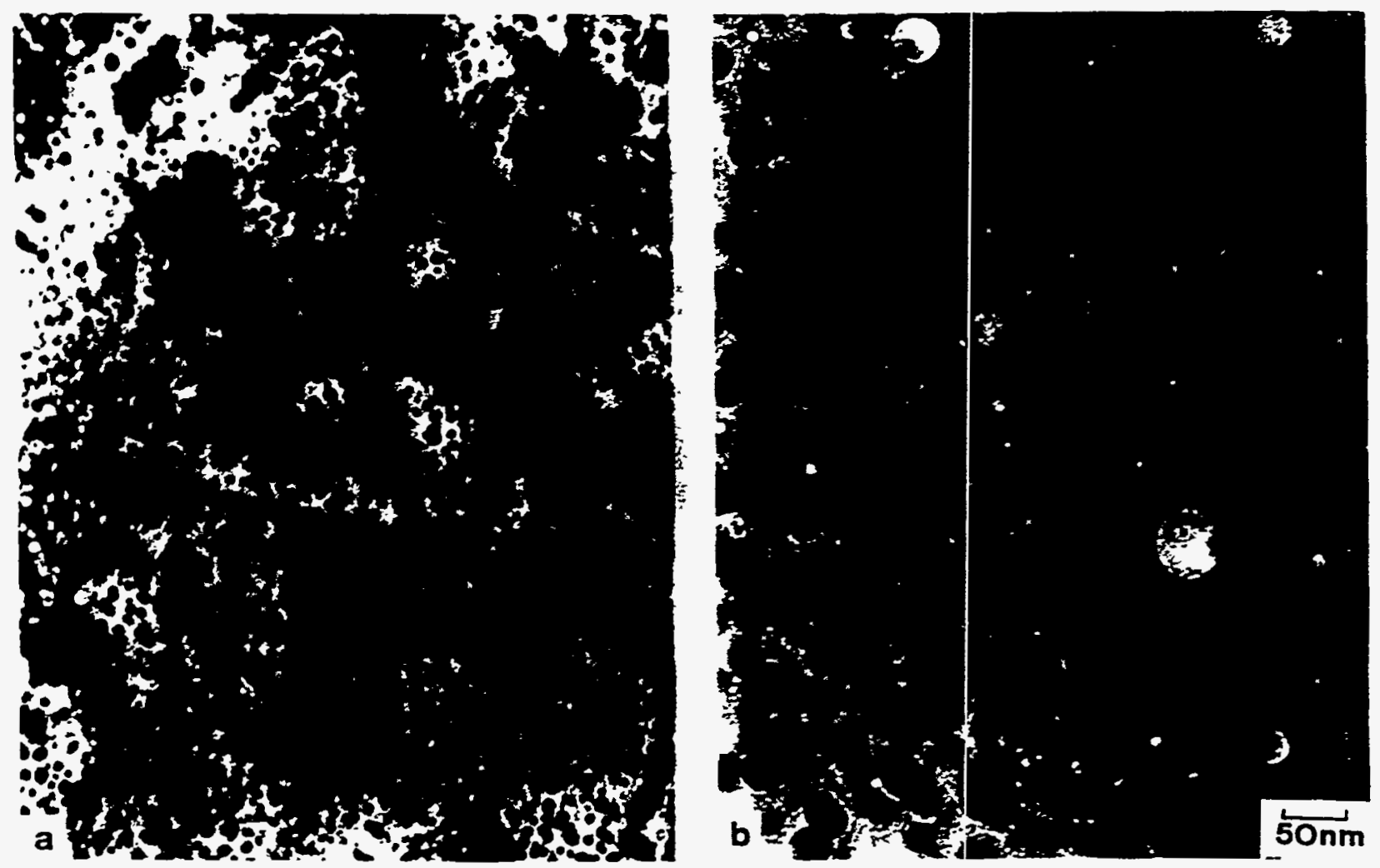

Figure 3. Microstructures of 6061-T6 aluminum alloy after high fluence irradiation in (left) the HFBR at $\Phi_{\mathrm{th}} / \Phi_{\mathrm{f}}=20$, and (right) the HFIR at $\Phi_{\mathrm{th}} / \Phi_{\mathrm{f}}=1.7$. 


\section{DISCUSSION}

Prima facie, the above evidence seems to uphold the thesis of a spectrum effect. The higher tensile strengths and the finer spatial distribution of the silicon precipitates in the HFBR materials obey the predictions for the effects of higher $\Phi_{\mathrm{th}} / \Phi_{\mathrm{f}}$ ratio. While this is encouraging, it is not proof of a spectral effect. Other explanations can be envisioned. The most obvious one is that the differences in tensile strengths and microstructural features described above might be symptomatic of a lower irradiation temperature for the HFBR materials. This explanation would be compatible with nuclear heating loads, which were less than $8 \mathrm{~W} / \mathrm{g}$ in the HFBR but were about $35 \mathrm{~W} / \mathrm{g}$ in the HFIR trap. Unfortunately, irradiation temperatures were not measured, and the issue can not be resolved with only the present data. It is noted, however, that the HFIR experiments were engineered to specifically accommodate the high heat load by ensuring sufficient flow of cooling water over the specimens, and there were no other signs that the goal temperature was not attained.

Temperature aside, the $\Phi_{\mathrm{th}} / \Phi_{\mathrm{f}}$ ratio is not the only variable in the HFIR and HFBR exposure conditions. There are differences in exposure times, fast and thermal fluxes, and fast fluences. For the microstructural comparison specimens, the exposure time for the HFIR specimens was $3.5 \mathrm{y}$, versus $20 \mathrm{y}$ for the HFBR material. The thermal flux was $2.7 \times 10^{19} \mathrm{n} / \mathrm{m}^{2} / \mathrm{s}$ for the HFIR and $6.4 \times 10^{18} \mathrm{n} / \mathrm{m}^{2} / \mathrm{s}$ for the HFBR. The fast flux was $1.6 \times 10^{19} \mathrm{n} / \mathrm{m}^{2} / \mathrm{s}$ for the HFIR and $3.2 \times 10^{17} \mathrm{n} / \mathrm{m}^{2} / \mathrm{s}$ for the HFBR. And the fast fluences were $1.8 \times 10^{27} \mathrm{n} / \mathrm{m}^{2}$ and $2.0 \times 10^{26} \mathrm{n} / \mathrm{m}^{2}$, respectively. The exposure times are only approximate because they include outages for refueling, etc. Nevertheless, they serve to show that time is not a prime determinant in the observed ripening; ripening was greater in the HFIR specimens, which had the shorter exposure time.

In principle, the degree of nucleation of the silicon precipitates might be expected to affect the final precipitate concentrations. Presumably, nucleation will be governed by the instantaneous supersaturation of silicon in solid solution, which will. vary with thermal flux. In which case, the HFIR specimens, with their five-fold higher thermal flux should yield the higher concentration of particles. On the contrary, the HFBR materials displayed the greater concentrations. This discrepancy can not be attributed to the somewhat higher silicon levels in the HFBR materials; nucleation must have ceased long before the final silicon levels were reached. We must conclude that either the supposed connection of nucleation with thermal fluence is wrong or that precipitate ripening has masked the actual nucleation behavior.

Differences in fast neutron flux and fast fluence are the remaining contenders for the cause of the microstructural differences. The presence of the silicon-coated voids in the HFIR specimens testifies to the effectiveness of the 12 times higher fast fluence in promoting movement of vacancies and silicon atoms, and makes a strong case for particle ripening controlled by fast neutron dose. But the large factor of 50 higher fast flux for the HFIR specimens offers an alternative route. An increase in dose rate may promote precipitate ripening by allowing more point defect transport. For the case when loss of point defects is dominated by bulk recombination, the steady-state vacancy concentration varies as the square root of the flux ${ }^{10}$, and a rough guide to the relative point defect diffusion currents is given by;

$$
\frac{\text { Diffusion current }_{(\mathrm{HFIR})}}{\text { Diffusion current }_{(\mathrm{HFBR})}} \propto \frac{\mathrm{t}_{(\mathrm{HFIR})} \sqrt{\Phi_{(\mathrm{HFIR})}}}{\mathrm{t}_{(\mathrm{HFBR})} \sqrt{\Phi_{(\mathrm{HFBR})}}}=\frac{3.5 \sqrt{50}}{20 \sqrt{1}}=1.23,
$$

where, for simplicity, time is in years and the fluxes are ratioed to the HFBR value. 
For the case in which most of the point defects are lost to sinks, the appropriate expression ${ }^{10}$ is

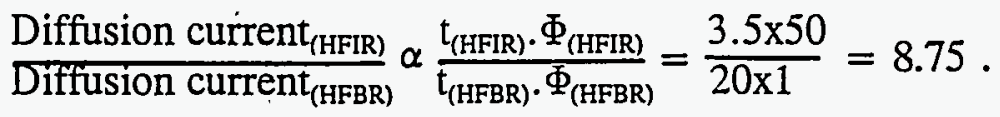

Thus, for both of these cases, the higher dose rate in the HFIR irracliations may have increased the level of atomic transport. This offers the prospect of a dose rate effect within a spectral effect, and adds another element of complexity to the situation.

If these data truly represent a spectral effect, not an inadvertent temperature effect, definitive spectral experiments under controlled conditions of temperature and dose rate are needed to resolve the issues raised herein.

\section{REFERENCES}

1. K. Farrell, J. O. Stiegler and R. E. Gehlbach, Metallography, 3 (1970) 275-284.

2. J. R. Holland, L. K. Mansur, and D. I. Potter, eds., Phase Stability Under Irradiation, pub. Met. Soc. AIME (1981).

3. D. S. Gelles, pp 562-582 in Effects of Radiation on Materials: Tenth Conference, ASTMSTP 725, Amer. Soc. Testing and Materiais (1981).

4. F. V. Nolfi, Jr., ed., Phase Transformations During Irradiation, Applied Science Publishers (1983).

5. J. R. Weeks, C. J. Czajkowski and P. R. Tichler, pp 441-452 in Effects of Radiation on Materials: 14th International Symposium (Vol.II), ASTM-STP 1046, Amer. Soc. Testing and Materials (1990).

6. J. R. Weeks, C. J. Czajkowski and K. Farrell, pp 1168-1182 in Effects of Radiation on Materials: 16th International Symposium (Vol.II), ASTM-STP 1175, Amer. Soc. Testing and Materials (1993).

7. K. Farrell and S. T. Mahmood, unpublished data, Oak Ridge National Laboratory, 1994.

8. K. Farrell and R. T. King, pp 440-449 in Effects of Radiation on Structural Materials, ASTM STP 683, Amer. Soc. Testing and Materials (1979).

9. K. Farrell, "Microstructural Analysis and Assessment of a HFBR Control Rod Drive Follower Tube", ORNL report in progress, Oak Ridge National Laboratory, 1994.

10. R. E. Stoller and L. K. Mansur, pp 52-67 in Proceedings of Alushta Conference on Radiation Materials Science, Kharkov, May 22-25, 1990.

\section{DISCLAIMER}

This report was prepared as an account of work sponsored by an agency of the United States Government. Neither the United States Government nor any agency thereof, nor any of their employees, makes any warranty, express or implied, or assumes any legal liability or responsibility for the accuracy, completeness, or usefulness of any information, apparatus, product, or process disclosed, or represents that its use would not infringe privately owned rights. Reference herein to any specific commercial product, process, or service by trade name, trademark, manufacturer, or otherwise does not necessarily constitute or imply its endorsement, recommendation, or favoring by the United States Government or any agency thereof. The views and opinions of authors expressed herein do not necessarily state or reflect thos: of the United States Government or any agency thereof. 